\title{
A hidropolítica e o federalismo: possibilidades de construção da subsidiariedade na gestão das águas no Brasil?*
}

\author{
Sandra Inês Baraglio Granja** \\ JEROEN WARNER
}

S U MÁRIo: 1. A hidropolítica e o federalismo brasileiros; 2. O federalismo e a gestão das águas; 3. A institucionalidade da gestão da água e os desafios da subsidiariedade; 4. Elementos para a construção de subsidiariedade numa gestão democrática das águas; 5 . Conclusões parciais.

Summary: 1. Brazilian hydropolitics and federalism; 2. Federalism and water management; 3 . Institutionality of water management and the challenges of subsidiarity; 4. Components for the construction of subsidiarity in a democratic water management; 5. Partial conclusions.

Palavras-CHAVe: gestão das águas; hidropolítica; federalismo; subsidiariedade; democracia.

KEY WORDS: water management; hydropolitics; federalism; subsidiarity; democracy.

Este artigo pretende mostrar como a hidropolítica do país se relaciona com o federalismo brasileiro e como construir um modelo de subsidiariedade na gestão das águas no território nacional, considerando os 26 estados e os

\footnotetext{
* Artigo recebido em dez. 2005 e aceito em ago. 2006.

** Doutoranda da Universidade de São Paulo (USP); mestre em ciência política pela PUC-SP; técnica da Fundação do Desenvolvimento Administrativo (Fundap). Endereço: Rua Cristiano Viana, 428 - CEP 054902-000, São Paulo, SP, Brasil. E-mail: sines@usp.br.

$* * *$ Cientista político, docente e consultor em políticas de recursos hídricos. Autor de diversos artigos e livros publicados sobre conflitos envolvendo água e participação. Doutorado em gestão de políticas de inundação pela Wageningen University, Holanda. Endereço: Disaster Studies Group - Wageningen UR - Hollandseweg 1 - 6706 KN Wageningen, Holanda. E-mail: jeroenwarner@gmail.com.
} 
mais de 5.500 municípios e o Distrito Federal, ou seja, a relação entre o recorte administrativo-político e o do gerenciamento de recursos hídricos. O artigo discute como o sistema político do país se relaciona com os fóruns da água, essencialmente com representações de prefeitos e agências governamentais, eleitas democraticamente e que irão ocupar os assentos de comitês de bacia. Diante de tamanho desafio, considerando que a água é um bem público de primeira necessidade que afeta a vida cotidiana de milhões de pessoas no Brasil, que variáveis devem ser levadas em conta nesse debate? $\mathrm{O}$ artigo aposta na necessidade de construção de um federalismo de cooperação que alavancará a subsidiariedade na gestão das águas.

Hydropolitics and federalism: possibilities of building subsidiarity in Brazilian water management?

This article reflects on how Brazil's water policy can be reconciled with its federalist setup, and on how the model of subsidiarity in national water management can be developed, considering that the boundaries of the mandates of the administrative patchwork of 26 states, over 5,500 local authorities and the Federal District do not coincide with the logical boundaries of water management (basins). It discusses how the political system relates to the basin management forums, essentially as democratically elected representatives of government agencies, who sit on of the basin committee. Given that water is a basic necessity in the daily lives of millions of Brazilians, which key variables need to be taken into consideration in this debate? The article advocates a cooperative kind of federalism as a lever for subsidiarity in water management.

\section{A hidropolítica e o federalismo brasileiros}

Com muitas definições de federalismo e diversos estudiosos no assunto, não pretendemos exaurir a discussão sobre o que é o federalismo e como pode ser compreendido. ${ }^{1}$ A preocupação maior é encontrar nessas definições elementos que possam oferecer espaços de reflexão que agreguem o federalismo, a hidropolítica e a gestão das águas no Brasil. Para Celso Furtado, federalismo "é o conceito mais amplo que tem sido utilizado para expressar a idéia de que a organização política deve basear-se na solidariedade e na cooperação, não na compulsão".

\footnotetext{
${ }^{1}$ A palavra federação vem do latim foedus que significa pacto, ou seja, pacto para governar, pacto de poder; união sob condições pactuadas, implica também em governos subnacionais, autonomia relativa, financeira, política, administrativa, entre outros.
} 
Francisco de Oliveira nos brinda:

\begin{abstract}
Resumidamente, a Federação é um pacto em que as partes (Estados soberanos ou Estados que poderiam ter se constituído como soberanos) renunciam, em grau muito alto, exatamente aos atributos da soberania: independência, moeda própria, monopólio da violência, controle do território, controle das populações, relações externas, regulação da economia... À renúncia dos diretos de soberania, correspondem deveres da Federação para com as partes federadas. O dever político: todas as partes devem poder partilhar o poder federal. Seguem-se deveres como a da segurança interna e externa. Mas constitui também dever da Federação uma eqüitativa distribuição da riqueza produzida exatamente pela "economia política" da Federação.
\end{abstract}

Entre as várias especificidades da federação brasileira a visão a seguir busca identificar traços gerais da realidade brasileira, tem caráter esquemático, portanto, não pretende esgotar os aspectos dessa realidade. Por vezes, aponta-os de forma caricatural, para ressaltar suas características hegemônicas. Especificidades que se iniciam com uma acentuada disparidade socioeconômica distribuída numa amplitude continental, permeada pela complexidade do aparelho de Estado e com fraca institucionalidade (demonstrada ad infinitum em diversas políticas públicas confessamente não implementadas) e com uma das piores distribuições de renda do mundo. ${ }^{2} \mathrm{O}$ país demonstra grande heterogeneidade regional; embora a Região Norte seja a maior do país, é a que tem menor população, com baixo PIB, pobreza e maior disponibilidade de recursos hídricos, como demonstra a tabela; a Região Nordeste, com pobreza acentuada e PIB baixo, igualmente é a que menos tem água; as regiões CentroOeste e Sul são as mais homogêneas no país; e a Sudeste carrega a dificuldade de distribuição de suas riquezas. Índices combinados de indicadores sociais e conflitos da água mostram como enfrentar os problemas de natureza políticoinstitucional na gestão dos recursos hídricos.

A gestão de recursos hídricos no país está em transição entre dois paradigmas, em larga medida caracterizada pela "missão hidráulica", onde o Estado lidera a exploração dos recursos hídricos. A construção de grandes projetos hídricos ou a reversão de água entre bacias, ou mesmo a hidrovia são exemplos de projetos iniciados de "cima para baixo", de forma tecnocrática, sem consulta prévia à população.

2 Estimado um PIB per capita anual de aproximadamente US\$ 4.000. 
Entretanto, a diversificação e modernização da economia brasileira, assim como o crescente aumento da consciência ambiental, tornou possível manifestos e movimentos de organizações não-governamentais (ONGs) questionando o modelo de desenvolvimento (modernização reflexiva) e demandando formas de decisão dialógicas ao invés de monológicas. Ao mesmo tempo, governos buscam referenciar os problemas de alocação de quantidade e qualidade de água, introduzindo a questão do apreçamento da água.

A Constituição de 1988 acolhe essas preocupações, contemplando a sociedade civil no gerenciamento da água em forma de plataformas consultivas e deliberativas, onde os atores pudessem participar: os comitês. Isso significa uma inquestionável dominância do governo no modelo hobbesiano, modelo de prevalência do Estado. A questão é: qual é o tipo do Estado brasileiro? Hobbesiano? Lockeniano ou rosseauniano? Que contrato temos entre o Estado e a questão da água? ${ }^{3}$ Com quem é exatamente o contrato, com o Estado ou com a federação? As cinco regiões brasileiras são diferentes entre si, com diferentes contextos hidrológicos e socioeconômicos, o que pode instigar a pergunta se não há diferentes tipos de contratos entre os cidadãos e o Estado e entre os cidadãos e a federação.

\begin{tabular}{|lccc}
\hline \multicolumn{4}{c}{$\begin{array}{c}\text { Distribuição dos recursos hídricos, da superfície e da população } \\
(\% \text { do total do país) }\end{array}$} \\
\hline Região & Recursos hídricos & Superfície & População \\
\hline Norte & 68,50 & 45,30 & 6,98 \\
Centro-Oeste & 15,70 & 18,80 & 6,41 \\
Sul & 6,50 & 6,80 & 15,05 \\
Sudeste & 6,00 & 10,80 & 42,65 \\
Nordeste & 3,30 & 18,30 & 28,91 \\
Total & 100,00 & 100,00 & 100,00 \\
\hline
\end{tabular}

Fonte: Dnaee, 1992. Disponível em <www. uniagua.org.br/website/default.asp?tp=3\&pay=aguaplaneta.htm>. Acesso em dez. 2006.

\footnotetext{
${ }^{3}$ Essa questão deve ser colocada e analisada, não nesse artigo sob a perspectiva do Hidro Social Contract Theory - HSCT, que discute a interação da relação entre o Estado, sociedade e recursos - ou seja, os bens comuns, em outras palavras, governança. A crise da água necessita de renegociação dos contratos entre Estado e sociedade? O HSCT trata do papel do Estado na proteção dos bens comuns. Essa discussão é profunda e envolve o entendimento do estado hobbesiano e a discussão da "missão hidráulica" e discursos relativos à escassez da água em algumas regiões (Warner, 2004).
} 
Assim, o federalismo brasileiro ${ }^{4}$ é o sistema que institui a divisão de responsabilidades e autonomia entre os governos federal, estadual e municipal. Embora apostemos, neste artigo, num federalismo de cooperação onde os atores possam construir sob critérios democráticos o que se quer para o país, os vários problemas existentes hoje podem paralisar essa pretensão de construção de um modelo de subsidiariedade da água.

No caso brasileiro, as competências comuns e concorrentes em nosso federalismo ${ }^{5}$ apontam para um federalismo de cooperação e integração, sucessor do federalismo de competências exclusivas e privativas.

\section{O federalismo e a gestão das águas}

A discussão da gestão das águas no Brasil tomou corpo em São Paulo no início da década de 1980 e passou por inúmeros debates. Incluído na Constituição Estadual de 1989, instituído pela Lei no $7.663 / 91$ e regulamentado pelo Decreto $\mathrm{n}^{\underline{0}} 36.787$ de maio de 1993, o Sistema Integrado de Gerenciamento de Recursos Hídricos do Estado de São Paulo (SIGRH) ${ }^{6}$ objetiva a execução da política estadual de recursos hídricos e a formulação, atualização e aplicação do Plano Estadual de Recursos Hídricos (Perh), congregando órgãos estaduais, municipais e entidades da sociedade civil.

No contexto federal, o Sistema Nacional de Recursos Hídricos começou a se cristalizar com a Lei n⿳⺈ 9.433, de 8 de janeiro de 1997, instituindo a política nacional de recursos hídricos e a promulgação da Lei no 9.984 de 17 de julho de 2000, que criou a Agência Nacional de Águas (ANA).

O Sistema Nacional de Recursos Hídricos compõe-se de sistemas federais, estaduais, regionais e locais, organicamente constituídos, destinados ao exercício articulado ou integrado das diferentes ações públicas em toda a bacia hidrográfica, como:

\footnotetext{
${ }^{4}$ Atualmente, poucos são os países do continente americano que exercem o federalismo. Na América do Sul, por exemplo, apenas Brasil, Argentina e Venezuela.

${ }^{5}$ Vale ressaltar que os anos 1980 foram marcados pela democratização do país, movimentos de descentralização desordenada e revigoramento da federação no Brasil, traduzidos pelo reforço da Constituição de 1988; eleições diretas; descentralização da receita, beneficiando principalmente os municípios, e, na outra ponta, aumento das competências e atribuições dos governos subnacionais nas despesas públicas com salários, custeios, investimentos em educação, saúde, saneamento etc. ${ }^{6}$ A existência do SIGRH constitui um feito: seus princípios básicos estabelecidos por lei: descentralização, participação e integração, seus órgãos e mecanismos estaduais e de bacias, seus planos de ação, seus recursos próprios e seus instrumentos de gestão devidamente definidos. É preciso aperfeiçoá-lo? Sempre. Vem funcionando por uma década, com avanços e retrocessos.
} 
v investimentos em infra-estrutura de saneamento, recursos hídricos, transportes e sistemas de comunicação;

v estudos e fixação de programas ecossocioeconômicos de desenvolvimento sustentável;

v planejamento, como atividade contínua, de caráter estratégico local, regional, estadual e federal;

v intervenções institucionais na organização e orientação espacial das atividades industriais, agrícolas, comerciais e turísticas;

v orientação dos processos de urbanificação e das políticas de uso e ocupação do solo na bacia hidrográfica;

v estabelecimento de políticas e controles ambientais de conformidade com a capacidade de intervenção dos diferentes órgãos normativos e operadores, de todos os níveis de governo;

v realização de obras, edificações e instalações de diversas naturezas e diferentes portes, exigindo a colaboração e recursos de todos os agentes executivos com atuação na bacia hidrográfica;

v instituição de fontes de recursos financeiros, bem como de mecanismos eficientes e adequados de arrecadação, especialmente os decorrentes do uso da água;

\ ação eficaz da polícia administrativa das águas, do solo, da flora e da fauna, visando ordenar, controlar e fiscalizar as atividades públicas e privadas na área de toda a bacia hidrográfica;

v composição de corpos institucionais, integradores de decisões multigovernamentais, com a participação dos usuários e demais membros da sociedade civil organizada, para a elaboração e implementação de políticas públicas na bacia hidrográfica, bem como de corpos de caráter administrativo e técnico para apoiar a normatização, o planejamento, a execução de ações públicas, o controle e a fiscalização das atividades na bacia hidrográfica como um todo (Alves, 1999).

A figura 1 demonstra as grandes bacias de âmbito federal, rios que passam por territórios, cidades, estados, conformação política do país - recorte administrativo que se inter-relaciona com o recorte hidrográfico. Para a convivência entre os sistemas de recursos hídricos - estaduais e federal, adotou-se, entre os comitês, o conceito de subsidiariedade, ou seja, em recursos hídricos as decisões e soluções dos conflitos de uso devem se dar na instância mais próxima das questões. O modelo brasileiro de gerenciamento da água foi igualmen- 
te orientado pelo federalismo e pelo princípio da subsidiaridade. Isso significa que tudo o que pode ser resolvido na escala local (associações de usuários ou organizações da sociedade civil) deve permanecer como tal.

Figura 1

\section{Bacias hidrográficas no território brasileiro}

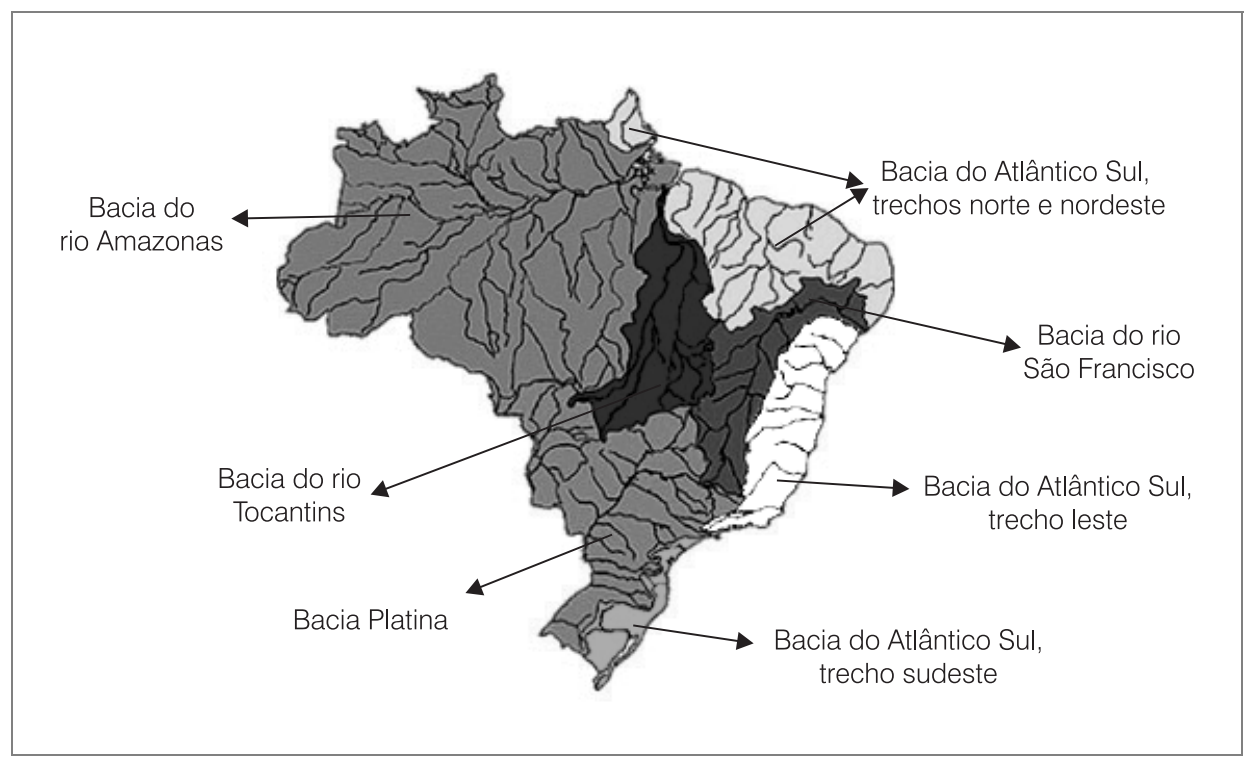

Se o modelo pretendeu legitimar um processo latente de ampla participação e de representação de interesses, na outra ponta é de condução altamente negociada (muitas vezes de difícil consenso), uma vez que pressupõe contemplar todos os interesses, sem perder de vista um cenário de recursos naturais e financeiros limitados.

Essas questões ${ }^{7}$ referentes à caracterização da representatividade dos membros, à definição das dominialidades ${ }^{8}$ e às conseqüentes relações de sub-

\footnotetext{
${ }^{7}$ Essas discussões passam pela Câmara Técnica de Assuntos Legais e Institucionais, do Conselho Nacional de Recursos Hídricos do país. Diversos comitês estaduais passam ou passaram pelo mesmo processo de entendimento dessas questões.

${ }^{8}$ Se um rio é de domínio da União é considerado federal e suas águas são de domínio federal, com exclusão do domínio dos demais níveis de governo. Nessa hipótese, sua administração (da água) seria feita por órgãos federais, não podendo o estado, o Distrito Federal ou os municípios interferirem nessa administração, a menos que o governo federal o admitisse expressamente.
} 
sidiariedade serão sempre objeto de adequações nos sistemas (tanto federal como estaduais). Às vezes o caráter nacional é confundido com o conceito federal. Ou seja, muitos entendem que há subordinação de ações e políticas que deveriam ocorrer entre comitês de bacia e os comitês de sub-bacias em rios de mesmo domínio, para o caso de diferentes dominialidades. Outros entendem que o federalismo brasileiro coloca em igualdade todos os entes da federação e, portanto, essas questões são objetos de negociação, pois a Constituição Federal dá ao governo federal a atribuição de legislar sobre água, além do CNRH ser um conselho nacional.

Figura 2

Mapa da malha municipal do Brasil

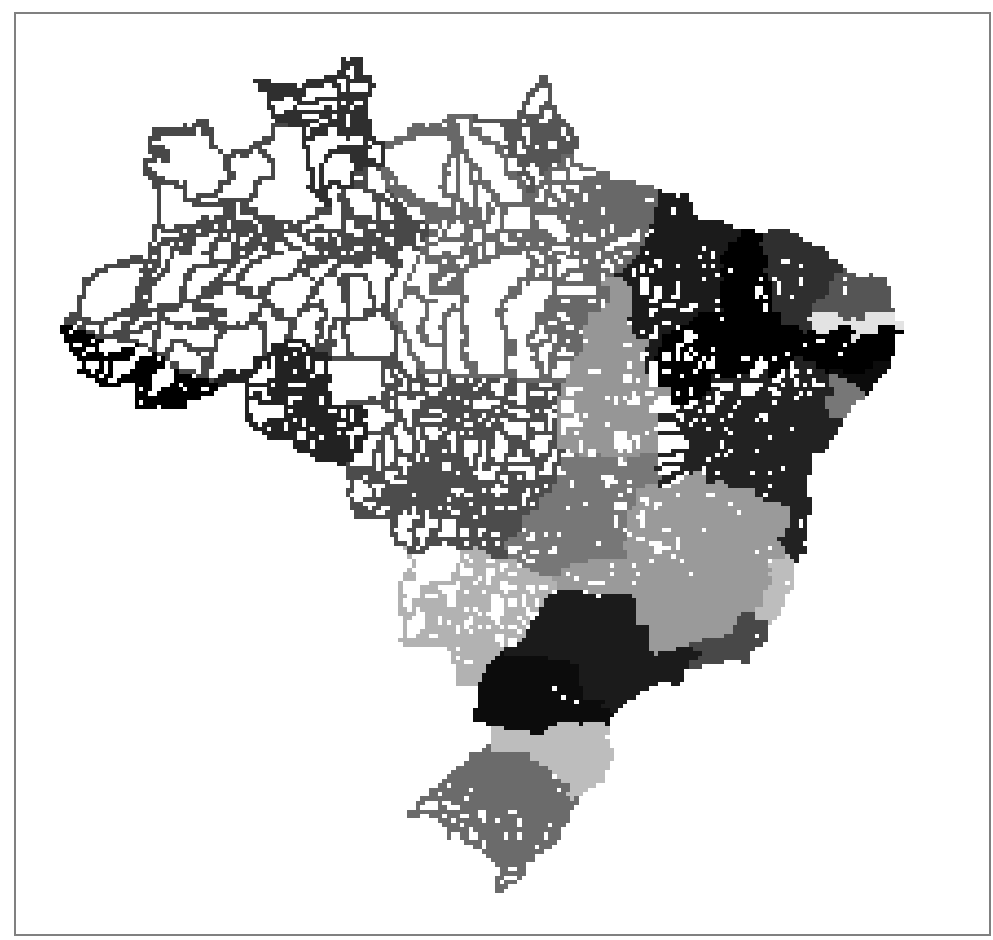

Fonte: IBGE, 2002.

Para que o Sistema Nacional de Gerenciamento de Recursos Hídricos se relacione com os sistemas estaduais há necessidade de esforços muito bem ar- 
ticulados institucionais, negociais, administrativos, técnicos, operacionais e financeiros dos estados federados e dos respectivos municípios envolvidos, ${ }^{9} \mathrm{em}$ conjunto com a União, objetivando correlacionar às ações de regulação, organização, planejamento, programação orçamentária e atividades operacionais de intervenção sobre a bacia hidrográfica correspondente.

Isso sem contar com o exercício de múltiplas competências das várias e diferentes agências governamentais de todos os níveis do governo federativo, cuja articulação e integração são indispensáveis ao gerenciamento da bacia. O Brasil tem 100 comitês de bacias hidrográficas espalhados pelo país. ${ }^{10}$

Qualquer sistema de gestão de recursos hídricos - estaduais ou federal - se configura como um mecanismo político e institucional que define a forma de participação do estado, dos municípios, dos usuários e da sociedade civil na execução das ações planejadas mediante a participação de todos os envolvidos em um ambiente de co-responsabilidade (Martins, 2001). Há no país pelo menos 100 comitês de bacia (CBHs), que promovem algum tipo de discussão em torno da água, muitos ainda em estágios de iniciação participativa, outros já modificando o arcabouço institucional para melhoria do desempenho da gestão. O comitê pode ser considerado o canal de comunicação entre a cidadania e o poder público. Será o meio que resolverá a panacéia e confusão setorial em que nos encontramos? De jeito nenhum, mas cabe perguntar se há como dinamizar a participação da sociedade civil na gestão das bacias.

Este artigo, além de apostar no federalismo de cooperação, também acredita que há um investimento processual: a questão da representação, ${ }^{11}$ que é uma ferramenta poderosa de mudança formada por mecanismos nem sempre digestos, pois sempre se discute o peso de cada uma dessas partes no processo decisório. No caso dos CBHs, a representação é paritária (esquema tripartite de representação) entre municípios, Estado (governo federal quando o rio é de domínio federal) e sociedade civil. Portanto, não se trata de um

\footnotetext{
${ }^{9}$ Desde os anos 1980 os municípios brasileiros vêm fortalecendo seu papel de gestores de políticas públicas. A Constituição de 1988 representou, para os governos locais, um significativo aumento de suas participações, muitos deles contemplaram em suas leis orgânicas capítulos de meio ambiente e/ou de recursos hídricos.

${ }^{10}$ Disponível em:<www.rededasaguas.org.br/forumn/forum_02.html>.

11 No âmbito de todas as instituições políticas abertas à participação da sociedade, sempre haverá algum interesse insurgido contra os critérios de representação que se encontrem em vigor. Sempre haverá alguém que se acha não-representado, mal representado ou sub-representado, ao mesmo tempo em que considera os interesses adversos sobre-representados.
} 
conjunto homogêneo, mas o sistema político-eleitoral funciona de modo que acate a vontade expressa nas urnas.

Os prefeitos e agências governamentais representantes do Estado ou do governo federal são membros de CBHs com as mesmas virtudes e desvios do nosso sistema eleitoral. Concordando com Martins (2001), o que acaba prevalecendo são as relações de poder ou as razões de conveniência. Assim, o que de melhor se pode fazer é assumir uma postura pragmática e adotar a tese de que o encaminhamento preferível para a questão da representação ${ }^{12}$ é aquele que, em cada conjuntura, for capaz de dar mais dinamismo e poder resolutivo aos comitês de bacia.

Há problemas entre nosso sistema político e nosso arcabouço institucional de gerenciamento da água? Sim, inúmeros, mas não se pode perder de vista que as instituições (tanto políticas, quanto administrativas e de gestão da água) são produtos de nossos contextos, portanto, espelham nossas escolhas, amparadas pela força e poder dos atores do jogo social naquela situação. ${ }^{13}$

Os comitês de bacia são instâncias de representação no sentido pluralista. Martins (2001:7) destaca que as instâncias pluralistas de representação encerram uma virtude e um vício específicos. O pluralismo é includente; e essa é a sua virtude. Ao contrário de outros esquemas de representação, o pluralismo não requer que cada um dos interesses afetados por uma determinada decisão tenha o direito de se fazer valer com o mesmo peso que os demais. Em compensação, porém, enquanto mecanismo abrangente e includente — vale dizer, plural —, o pluralismo requer que todos os interesses pertinentes possam se fazer ouvir, se assim o desejarem. O vício do pluralismo, por sua vez, encontra-se no método de resolução de conflitos que é típico desse modelo de representação. Nos termos do arranjo pluralista, os conflitos têm de ser resolvidos fundamentalmente por processos de negociação e conciliação que conduzam à acomodação dos interesses. Não se trata, pois, de contar votos e fazer prevalecer a vontade da maioria, mas, muito ao contrário, de encontrar soluções de compromisso entre as partes litigantes.

Aqui há necessidade de dupla entrada para compreender a questão, mesmo que o sistema de recursos hídricos expresse ou encaminhe questões

\footnotetext{
12 Existem diversos modelos diferentes de representação que podem (e devem) ser questionados sempre, na perspectiva de aprimoramento dos mecanismos de representação. Assim funciona a democracia. Mas as instituições representativas não são todas iguais; cada qual deve ser avaliada à luz do seu próprio conceito.

${ }^{13}$ Utilizam-se aqui os conceitos de jogo social e de atores com respectivas forças estratégicas, concebidos por Carlos Matus.
} 
pluralistas, na outra ponta há fragilidade dos direitos no país expressa em falhas: na legislação (leis que discriminam); na aplicação da lei, que pode ser discricionária, muitas vezes na impunidade aos privilegiados; nas relações entre as "burocracias" do Estado e os cidadãos comuns, com enormes dificuldades para estes e acesso fácil aos serviços públicos. Talvez a fragilidade dos direitos civis seja a chave para explicar a persistência de enormes desigualdades prevalecentes no Brasil, na medida em que eles fornecem a base para lutar por outros direitos (O’Donnell, 1991).

O sistema político está intrinsecamente vinculado ao sistema de gestão do país, repensar e melhorar qualquer um deles requer, necessariamente, fortalecer o outro, ou seja, como contra-exemplo a erosão da democracia em sistemas de eleição (para cargos executivos) contaminados contribui para a representação de atores frágeis em comitês de bacia, pois são os mesmos personagens. Muitos apostam na melhoria ou até na reforma do sistema político, o que imprimirá uma gestão mais qualificada, cristalizando o conceito da subsidiariedade na gestão das águas; entretanto, muitos apostam e jogam contra porque perdem poder discricionário na alocação dos recursos setoriais. Perdem também acesso privilegiado, ou abrigo das rotinas burocráticas, os nichos de interesses econômicos e políticos, porque perdem oportunidades de parasitar verbas setoriais (Martins, 2001).

O sistema partidário ${ }^{14}$ brasileiro, por sua vez, estrutura-se a partir de máquinas alimentadas de formas não transparentes com enorme número de cargos de confiança do setor público, o que compromete a democracia. Conforme Costa (2002:15),

a democracia representa uma forma de dominação consentida, na qual as decisões necessitam ser permanentemente fundamentadas e justificadas, dependendo sempre da comunidade política para que possam ser implementadas. Nesse processo, cabe à esfera pública um lugar central: ela se torna a arena onde se dá o amálgama da vontade coletiva quanto a justificação das decisões políticas previamente acertadas.

Ora, se há esse acesso a fatias do poder governamental, objeto de um tipo de partilha que tende a dificultar a cooperação, como construir uma ges-

\footnotetext{
14 Os partidos enfraquecem, então, sua função de intermediação entre a sociedade civil e o Estado. Confundem-se, muitas vezes, com o aparato estatal. Não atuam como ordenadores das demandas da sociedade. Transformam-se, muitas vezes, em instrumentos de realização de projetos pessoais de poder (Fundap, 2004).
} 
tão da água baseada num federalismo de cooperação e de subsidiariedade no gerenciamento de recursos hídricos?

\section{A institucionalidade da gestão da água e os desafios da subsidiariedade}

A institucionalidade construída para dar vazão às ações do modelo brasileiro de gestão das águas tem uma forte vinculação com a estrutura política do país. Muitas das agências governamentais das três esferas de governo constituem-se membros representantes em comitês de água, e mais, são os canais (dentro de suas estruturas organizacionais) que viabilizam concretamente as ações que precisam ser implementadas para que a gestão da água se materialize (abastecimento de água, esgoto sanitário, construção de cisternas, entre inúmeras outras ações). $\mathrm{O}$ rol de funções do gerenciamento de recursos hídricos é extenso, o que exige entendimento da situação (com "olhares" que contemplem a transdisciplinaridade e a complexidade) e priorização das intervenções, passando inclusive pela viabilização política.

As instituições do Estado brasileiro estão fundadas no conhecimento por setores, ou seja, se organizam por áreas de especialização, prevalecendo uma cultura fragmentada que dificulta a interação entre especialistas, que acabam criando resistências ao trabalho transdisciplinar, ${ }^{15}$ tornando difícil a explicação da gestão das águas de forma que capture a complexidade que lhe é própria. Quando a transversalidade e a complexidade não são consideradas para a gestão das águas, desenham-se programas inadequados, há dificuldade de negociá-los intra e interinstitucionalmente e com a sociedade (leia-se comitês de bacia), mobilizando recursos de diferentes naturezas, e de implementá-los, monitorá-los e avaliá-los.

Como aproximar conhecimentos complexos entre especialistas intra ou interinstitucionalmente que atuam nas esferas de governo ${ }^{16}$ e são representantes no sistema de gestão das águas, vencendo eventuais resistências ao tra-

\footnotetext{
15 Corresponderia a uma radicalização da interdisciplinaridade, pela articulação de um amplo conjunto de disciplinas em torno de um campo teórico e operacional particular, sobre a base de uma axiomática comum e envolvendo um sistema de disciplinas articuladas em diferentes níveis, cuja coordenação se daria pelas finalidades e axiomática comuns. Esse tipo de integração possibilitaria o desenvolvimento de teorias e conceitos transdisciplinares, cuja aplicação seria compartilhada por diferentes disciplinas e abordagens que atuariam num campo teórico e operacional. ${ }^{16} \mathrm{O}$ enorme contingente de cargos de confiança em nossa esfera pública é utilizado para acomodar interesses partidários. Com memória de baixa responsabilidade política agregada à rotatividade do poder, há tendência de apagar a memória da gestão da água construída anteriormente.
} 
balho cooperativo? Uma das possibilidades é a negociação permanente de forma intersetorial, transdisciplinar, ${ }^{17}$ intergovernamental e em relação direta com a sociedade civil.

Percebe-se que as instâncias do Poder Executivo passam mais tempo negociando disputas internas de poder do que com a sociedade civil, conseqüentemente fragilizando a democracia, porque atende interesses internos do governo para acomodar interesses conflitantes. O jogo negocial, que poderia estar voltado totalmente à gestão das águas, fica preso ao calendário das disputas eleitorais.

De imediato, as conseqüências mais significativas transparecem na fragmentação das ações governamentais; administração não-transparente e casuística; falta de visibilidade das ações governamentais e das contribuições específicas de cada área; programas que se superpõem e/ou conflitam; solução de problemas tocada de forma tangencial; não se potencializam os programas na plenitude em virtude da não-aglutinação da força da sociedade civil e de outras esferas de governo; baixa capacidade de aprendizado a partir da própria ação; baixo comprometimento do corpo de funcionários e baixa qualidade dos programas governamentais; alto custo das ações de governo; ineficiência e ineficácia do governo; descrédito da sociedade nos processos políticos e democráticos; dificuldades para a coordenação governamental; fortalecimento de poderes paralelos ao Estado (Fundap, 2004).

Será necessário, então, compreender e trabalhar de forma intersetorial (Inojosa, 2002). ${ }^{18} \mathrm{E}$ com o entrelaçamento do complexo, ou seja, o que está tecido em conjunto. Isso significa transcender a fragmentação departamentalizada da organização governamental e colocar-se em sintonia direta

\footnotetext{
17 É necessário fazer uma distinção entre a multidisciplinaridade como o conjunto de disciplinas que se agrupam em torno de um dado tema, desenvolvendo investigações e análises isoladas por diferentes especialistas, sem que se estabeleçam relações conceituais ou metodológicas entre elas. Corresponde à estratégia mais limitada, pois continuam a se reproduzir práticas fragmentadas da ciência normal, ainda que se avance na incorporação de múltiplas dimensões de um problema; e a interdisciplinaridade como a reunião de diferentes disciplinas articuladas em torno de uma mesma temática com diferentes níveis de integração. O que nos interessa neste artigo é a transdisciplinaridade.

${ }^{18} \mathrm{Na}$ esteira das teses ventiladas por Edgar Morin. A administração pública vem se dividindo em educação, assistência social, saúde, transporte etc., assim como as disciplinas em que o saber científico se divide, nasceram e se desenvolveram sob o signo da disjunção e do insulamento (Martins, 2001). Formaram-se assim, como diz Inojosa, cláusuras setoriais, cada qual com sua corporação, com sua linguagem própria, com sua lógica de funcionamento e sua maneira particular de compreender o contexto.
} 
com as expectativas e necessidades de populações que reclamam ser tratadas em realidades particulares, de natureza complexa, situadas em seu espaço territorial exclusivo. ${ }^{19}$

Embora a existência de CBHs represente um primeiro passo na institucionalização dessa interlocução com a sociedade, sua composição de representantes pode também apresentar maior ou menor vulnerabilidade. A estratégia mais efetiva para diminuir isso é a adoção de interlocução constante, acelerando o processo de desenvolvimento em ambos os lados.

Isso requer combater um sistema fortemente hierárquico, setorial, baseado na submissão e/ou cooptação das unidades subnacionais e também na desarticulação das esferas governamentais; um modelo que impede a coordenação das ações no âmbito nacional e estimula a competição predatória assim como a desresponsabilização, tanto vertical quanto horizontal, entre as esferas de governo. Como fazê-lo? Elegendo atores co-responsáveis para o Poder Executivo nas três esferas de governo que conseqüentemente irão ocupar os assentos dos fóruns de água, ou seja, homens públicos comprometidos a figurar promissoriamente nos sistemas de tipo cooperativo.

A cooperação é a pedra de toque de um federalismo ${ }^{20}$ robusto, combinada com muita negociação das partes constitutivas do todo federativo, com disposição para encontrar progressivas soluções aos imensos problemas do país, mesmo que isso signifique passar por processos de confrontação e luta política, que só acontecerá se mostrarmos capacidade de criar o espaço apropriado, ou seja, a esfera pública.

\section{Elementos para a construção de subsidiariedade numa gestão democrática das águas}

Os participantes dos sistemas de recursos hídricos - tanto federal quanto estaduais - são e serão os protagonistas essenciais para as mudanças necessárias, no sistema político brasileiro e no de gerenciamento da água, pelo voto

\footnotetext{
19 Tarefa que se mostra tanto mais difícil, como observa Rose Inojosa, quanto mais firmemente as fatias parcelares vêem-se loteadas por grupos de interesse, por definição resistentes a qualquer tentativa de integração.

${ }^{20}$ Sabe-se, entretanto, que isso pode ser uma visão romântica, como nos fala Martins (2001): "Infelizmente, porém, o federalismo cooperativo costuma extraviar-se nas ilusões criadas pela ingenuidade e alimentadas pela ideologia pseudodemocrática que prega a instituição de um sistema de relações intergovernamentais fundado na coexistência pacífica, harmônica e solidária entre os entes federados; é inevitável que as incompatibilidades e os conflitos se apresentem como dimensão constitutiva da realidade das relações intergovernamentais, tanto no sentido vertical, quanto no horizontal".
} 
em eleições. Algumas das ferramentas já estão nos próprios sistemas de gestão: participação, descentralização e integração de ações e afinidades eletivas com a concepção transdisciplinar da gestão e, sem dúvida o aproveitamento da rede já existente nos próprios comitês de bacias hidrográficas (CBHs). Há duas idéias implícitas na questão da rede: a própria rede de aprendizagem que se pode criar e fomentar entre comitês e sistemas de gerenciamento de recursos hídricos, bem como a idéia de fortalecimento das redes das próprias agências governamentais.

Figura 3

\section{Mapa geopolítico do Brasil}

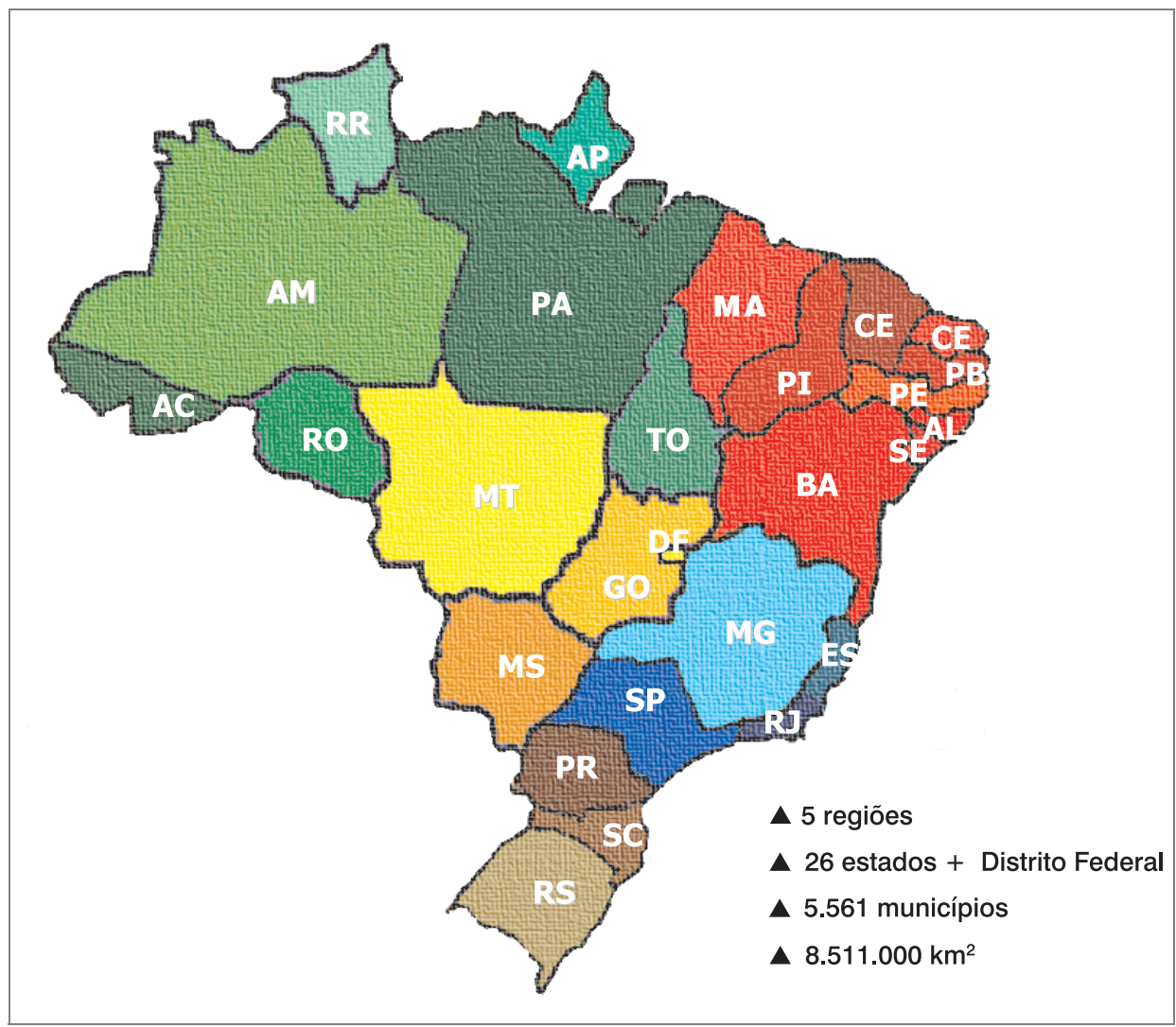

Fonte: Ministério da Educação. Disponível em: <www.untref.edu.ar/Brasil.ppt>.

Obs.: 0 censo demográfico de 2000 apontava o país com $8.514 .215,3 \mathrm{~km}^{2}$, composto por 27 unidades da federação e 5.507 municípios existentes naquela data. Diferente das informações de 2006 da apresentação do Ministério da Educação com 5.561 municípios. 
A figura 3 apresenta a geopolítica do país e as potenciais dificuldades na fragmentação de divisões administrativas (cinco regiões, 26 estados, um Distrito Federal e mais de 5.500 municípios) que num quadro ideal fariam a concertação com as divisões hidrográficas (ver figura 1). Tal concertação esbarra, entretanto, em temas cuja territorialidade ultrapassa claramente os limites do município (caso de questões ambientais e o caso de quase todas as questões ligadas à infra-estrutura urbana: tanto transportes como saneamento ou energia dificilmente estão circunscritos a um só município).

Por tudo isso, consideramos a necessidade de se investir fortemente em negociação, para possibilitar a articulação e a integração das ações públicas da União, dos estados federados, do Distrito Federal e dos municípios, nas diferentes bacias hidrográficas.

As exigências de um sistema federativo de cooperação e de integração, performando instituições, ações e atividades de todos os entes político-administrativos que, no exercício de suas respectivas competências, possam articulá-las e integrá-las para a consecução do desenvolvimento sustentável de qualquer bacia. O papel singular da União como coordenadora das ações interestaduais, preventiva de conflitos e asseguradora da harmonia das políticas estaduais com a política federal de recursos hídricos, no que respeita o gerenciamento das bacias ou sub-bacias hidrográficas, relacionadas com rios de seu domínio, assegurando-se sempre a participação paritária dos estados, Distrito Federal, municípios e usuários. Isso está embasado num federalismo de cooperação que pode colaborar na sustentação de um modelo de subsidiariedade (Alves, 1999).

Isso implica harmonização e composição das ações locais, regionais e estaduais, assegurando-se a articulação das políticas nacional e estaduais no âmbito dos recursos hídricos, bem como dos planos, programas e projetos correspondentes. Significa, então, considerar a bacia hidrográfica como uma unidade de planejamento estratégico, da adequabilidade de aplicação dos recursos financeiros, ${ }^{21}$ bem como das decisões acertadas ao nível da realidade, ficando as responsabilidades institucionais definidas somente a partir das soluções técnicas. Por isso, a importância do entendimento de que o voto produzirá melhores atores protagonistas para o gerenciamento dos recursos hídricos.

A figura 4 aponta as áreas das bacias hidrográficas no Brasil. A grande extensão territorial $\left(8,5\right.$ milhões de $\left.\mathrm{km}^{2}\right)$ e a distribuição dos recursos hídricos merecem um estudo aprofundado desse federalismo hídrico que deve ser

\footnotetext{
${ }^{21}$ A cobrança pelo uso dos recursos hídricos é considerada aqui como instrumento de condução das políticas públicas nas bacias hidrográficas.
} 
repensado em sua heterogeneidade de acentuadas desigualdades econômicas e sociais (entre regiões e grupos populacionais), alterações demográficas, estrutura etária, urbanização acelerada. Nosso federalismo está "em construção" com as tensões e impasses na definição do papel de cada esfera e nas relações intergovernamentais; cooperação versus conflitos no que se refere também à questão da gestão das águas.

Figura 4

Área das bacias hidrográficas no Brasil (\%)

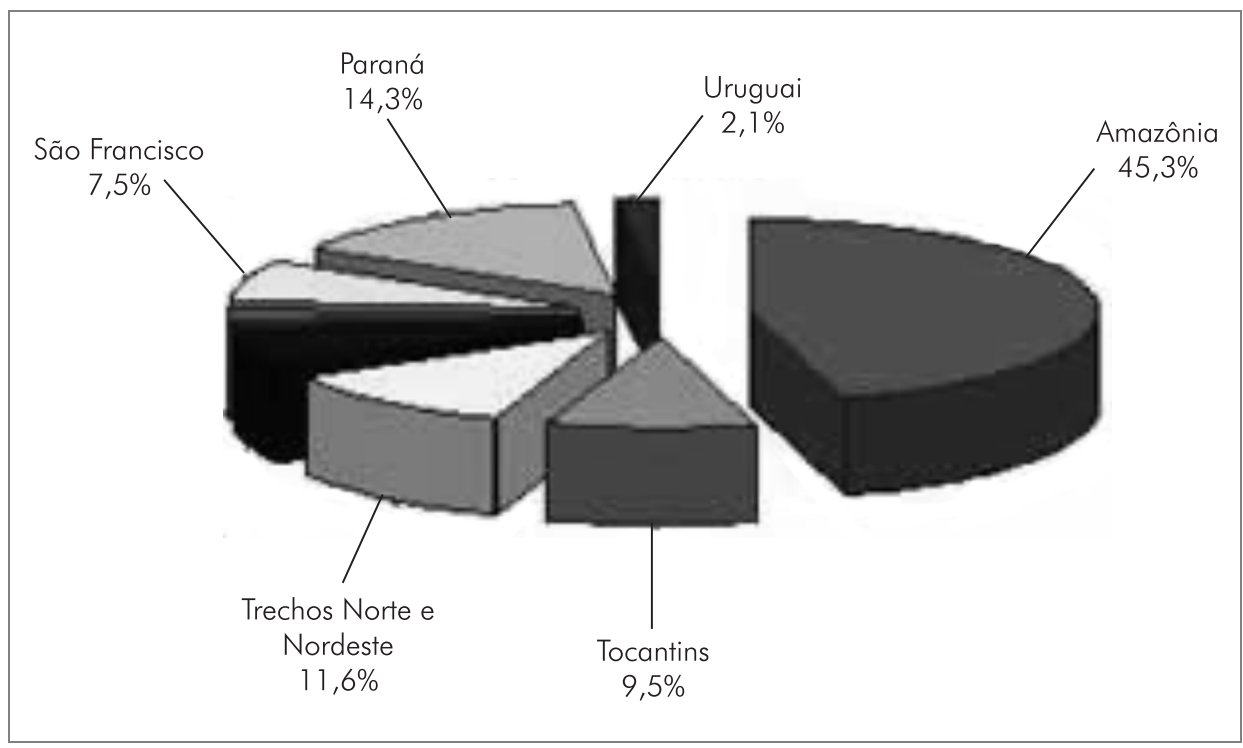

Esse federalismo de cooperação incorpora a variável política. Assim, cada vez mais os espaços institucionais de negociação e acordo político, em que as representações municipais estejam contempladas, estão respeitando proporcionalidades numéricas e político-partidárias e articulações territoriais. A destinação e a gestão dos recursos que as organizações detêm é que deverão ser objeto de negociação e acordo. O modelo de gestão, além de horizontal e não-hierarquizado, deve incluir a sociedade em suas representações regionais (bacias). O controle social da destinação dos recursos (accountability) e dos processos decisórios é importante para a participação no modelo de gestão da água. Assim, valoriza-se a construção de um capital social que permita o estabelecimento de uma governança da água. 
O debate sobre governança da água no Brasil não é ainda uma discussão aprofundada. Sinteticamente pode-se entender governança ${ }^{22}$ como um processo que envolve tomadores de decisão e não tomadores de decisão com objetivo comum: o problema a ser enfrentado e o desenho da gestão para a água, onde a participação descentralizada e co-responsável sejam a tônica do processo. Pressupõe atuação em rede, atuação integrada; o ganho de poder dos atores envolvidos na gestão, interagindo com os tomadores de decisões relativos aos recursos hídricos.

O fortalecimento da governança da água pode ter muitas estratégias (institucionais ou não), como as arenas de negociação, as práticas educativas e a participação da sociedade civil, ferramentas para contribuir no processo de construção de tomada de decisão compartilhada sobre a gestão das águas.

O processo de negociação em comitês de bacias hidrográficas é um fenômeno interessante e não totalmente compreendido porque não há clareza dos motivos pelos quais essas arenas fracassam ou obtêm sucesso. Embora as negociações se desenvolvam em diversas dimensões, optou-se por estudá-las em CBHs. E por que a escolha da bacia hidrográfica? Mesmo que a realidade ecossocioeconômica ocorra num contínuo territorial incontornável, cuja complexidade não se atém a um espaço institucionalmente recortado e fragmentado, a bacia é a unidade físico-territorial de planejamento e gestão adotada no país.

A bacia é vista como "camadas" que podem ser vistas com lentes translúcidas para a compreensão de sua realidade: fatores físico-naturais; complexos socioeconômicos; recortes de fronteiras institucionais; procedimentos políticos de decisão (Wester e Warner, 2002). O que resta saber, nas arenas de negociação, é se essas divisas artificiais despotencializam ou não a intervenção sobre a região ou a bacia hidrográfica como um todo, representando antes um fator de irracionalidade que deve ser superado, com políticas organicamente articuladas e integradas.

\footnotetext{
${ }^{22}$ Water governance refers to the various levels of political, social and administrative mechanisms that must be in place to develop and manage water resources including the delivery of water services. (...) To achieve good governance for water it is necessary to create an enabling environment which facilitates the following: efficient private and public sector initiatives; a regulatory regime which allows clear transactions between stakeholders in a climate of trust; and shared responsibility for safeguarding river and aquifer resources whose management affects many people but at present is frequently the responsibility of none (<www.epe.be/objective2002/cairo/invitationwgover.html >).
} 
Então, a continuidade da construção de uma institucionalidade do sistema de gerenciamento de recursos hídricos está baseada no conceito de subsidiariedade, que, por sua vez, é intrinsecamente vinculada ao federalismo cooperativo que se vincula ao sistema partidário-político brasileiro. Talvez, como a água é um bem público essencial à vida seja preciso politizar cada vez mais sua discussão, pois há direitos e co-responsabilidade em sua gestão.

\section{Conclusões parciais}

A despeito de muitos questionamentos ainda existentes, a questão principal é: o que estamos pactuando? As possibilidades de desenvolvimento? E em relação à gestão das águas: por que continuamos juntos? Uma das inúmeras respostas para esse dilema: o que nos une é a possibilidade de juntos sermos fortes e com maiores chances de construir um futuro negociado para o país.

A formação dos conselhos ${ }^{23}$ (entre eles a figura institucional dos comitês de bacia hidrográfica) representa um enorme avanço inscrito na Constituição Federal de 1988. Ela o coloca como mecanismo de participação popular na formulação e gestão de políticas públicas. Sua estruturação, que se estende pelas três esferas de governo, abriria espaço para a edificação de um federalismo cooperativo. A relação dos comitês com a sociedade civil resolve os problemas de conflitos de água no país? Não, de forma alguma, há queixas sobre o distanciamento dos interesses prioritários da sociedade civil em relação ao uso das águas, assim como sobre o despreparo e a falta de motivação por parte de muitos integrantes dos sistemas de recursos hídricos (tanto estaduais quanto federal) ou sobre o apoio insatisfatório que as entidades dão aos seus representantes.

O eleitor precisa compreender cada vez mais que seu voto promove ou paralisa melhores condições de gestão da água, por meio da transferência de poder decisório. Há uma mão dupla aqui, ao eleger seus representantes políticos o eleitor pode ter seu candidato como participante das estruturas institucionais da gestão da água, mas também pode participar como sociedade civil ou mesmo ouvinte nos fóruns da água. Isso pode contribuir para um governo mais acessível ao cidadão, aumentando a participação direta da cidadania e o

\footnotetext{
23 Os conselhos podem ser de diversas áreas, como saúde, educação, assistência social, recursos hídricos, entre outros. Representam experiências de coordenação dessas políticas em cooperação com as demais esferas de governo, o que torna rico seu aproveitamento para aperfeiçoá-las e entender a contribuição dos conselhos em sua formulação e gestão.
} 
controle e responsabilização social. A ampliação da participação pode empurrar a gestão pública ${ }^{24}$ na melhoria de seus patamares de gestão, como a possibilidade de aumento da eficiência dos governos.

Associaremos aqui a necessidade da gestão pública agregar-se cada vez mais à implementação das estratégias de negociação. Para isso, propõe-se trabalhar com o conceito de joined-up government ou JUG, ${ }^{25}$ que basicamente se refere à governança conjunta com modelos de partilha de poder, com diversas tipologias combinadas ou não. Embora seja difícil definir JUG, sua literatura é recente e eclética. Pode-se dizer que há participação de atores de diversas naturezas, inclui vários níveis de governo, empresas, associações voluntárias, cidadãos etc. É permeado pela horizontalidade das ações e sinergias podem ser criadas pelos diferentes atores, com campos particulares da política ou rede. $\mathrm{O}$ JUG amplia o rol de serviços aos cidadãos. Sua dimensão política está na tensão entre democracia representativa e participativa; não é algo que o governo decide "fazer", é um projeto cooperativo de longo prazo.

O JUG persegue algumas características essenciais, como a horizontalidade e sinergia, que devem ser criadas pelos diferentes atores, com campos particulares da política ou da rede. O JUG só tem sentido quando entendido na perspectiva de ampliar o rol de serviços prestados aos cidadãos, ou seja, quem responde o que na prestação de contas da política pública (accountability). É o caso dos comitês de bacias que precisam prestar contas de suas atividades na melhoria da gestão à população. Da mesma forma que os atores das agências governamentais devem prestar contas de suas ações.

No caso brasileiro, é imprescindível considerar o JUG nos modelos federativo e de subsidiariedade, não como representante adicional ao pacto fe-

\footnotetext{
${ }^{24}$ Em nível regional, os consórcios também têm contribuído para a gestão pública. Geralmente com formato de sociedade civil de direito privado, os consórcios são compostos por prefeitos, podendo ocorrer também composições mistas, como prefeitos e representantes de empresas que têm como objetivo principal representar o conjunto dos membros integrantes em matérias de interesse comum; atuam principalmente na solução de problemas locais afetos aos municípios, como lixo, esgoto, reflorestamento, educação ambiental, saúde etc. As decisões são tomadas pelo conjunto dos membros integrantes do consórcio, na forma prevista em seus estatutos e dependem da contribuição dos consorciados ou recursos advindos de agências financeiras nacionais e internacionais para implementação de suas ações. Existem vários consórcios espalhados pelo país.

${ }^{25}$ Pollitt (2003). Pode-se afirmar que o JUG tem quatro metas principais: eliminar tensões e contradições entre as diferentes políticas; uso eficiente do recurso (eliminando duplicação de programas); impulsionar o fluxo de boas idéias e cooperação entre os diferentes atores e produzir serviços estruturados sob o ponto de vista do beneficiário final.
} 
derativo, mas como elemento atávico do processo de entendimento da política pública e sua tradução na execução.

Para criar JUG é preciso moldar operações de sistemas que promovam a flexibilidade, inteligibilidade mútua, accountability mútua; trocas financeiras e performances ligadas entre parceiros. A disponibilização de recursos e o desenvolvimento da cultura da confiança e de solução (gerenciamento seqüenciado estrategicamente) conjunta de problemas são elementos essenciais para a criação de processos executivos, incluindo elementos de processos políticos.

Embora o governo não seja um ator neutro e ingênuo para a gestão de bacia, é um ator fundamental que por meio de suas instituições pode promover ou não a alocação de recursos necessários para a melhoria da gestão de água. Portanto, é um ator que não deve ser desconsiderado. Deve-se, sim, procurar em suas entranhas onde e como promover JUG para desenvolvimento de estratégias que beneficiem a gestão dos recursos hídricos.

A abertura de espaços de participação e a cristalização dos já existentes, embora sejam condição necessária, não são suficientes para que a gestão das águas continue em sua jornada político-institucional, porque de um modo geral há limites de participação; a sociedade civil acaba, muitas vezes, não conseguindo, nos comitês, interferir significativamente na agenda governamental, uma vez que sua própria agenda é empobrecida. De qualquer forma, são espaços que podem ser aproveitados para construir agenda de programas relativos à água. Aliado ao JUG, talvez seja possível diminuir a setorialidade, reduzindo eventuais resistências de comunidades e feudos epistêmicos.

Assim, acreditamos que a negociação agregada ao JUG pode fomentar um federalismo cooperativo para a gestão das águas, baseado no conceito de subsidiariedade ao abrir espaço, de forma propositiva, para o envolvimento de outras esferas de governo na solução dos conflitos relativos aos usos da água.

Isso pode diminuir a fragilidade da esfera pública, já que os atores contribuem na arena estruturada para enfrentá-lo(s) - no caso aqui, os comitês de bacia. Há limites nesta abordagem? Sim. Os três elementos: o sistema políticopartidário-representativo, o federalismo e a gestão das águas sustentada no conceito de subsidiariedade não estão alinhadas e caminham necessariamente ao mesmo passo. Isso significa revezes, avanços, novos olhares, avaliações e disposição de negociação estratégica. Quanto mais complexa a junção desses elementos, mais conectividade haverá entre as políticas públicas neste país.

\section{Referências bibliográficas}

ABRUCIO, F. L. Os barões da federação. São Paulo: USP, Hucitec, 1998. 
AFFONSO, Rui. Os estados e a descentralização no Brasil. Santiago de Chile: Cepal/GTZ, 1997. (Série Política Fiscal 93).

; Pedro Luiz Barros (Orgs.). A federação em perspectiva: ensaios selecionados. São Paulo: Fundap, 1995. p. 57-75.

ALMEIDA, Maria Hermínia Tavares de Almeida. Federalismo e políticas sociais. In: AFFONSO, Rui de Britto Álvares; SILVA, Pedro Luiz Barros (Orgs.). Descentralização e políticas sociais. São Paulo: Fundap, 1996. p. 13-40.

ALVES, Alaôr Caffé. O problema das competências constitucionais em matéria ambiental, relações e conflitos entre União, estados e municípios. 1999. ms.

Regiões metropolitanas, aglomerações urbanas e microrregiões: novas dimensões constitucionais da organização do Estado brasileiro. Revista de Direito Ambiental, São Paulo, v. 6, n. 21, p. 57-82, 2001.

. As cidades e o federalismo brasileiro. 2004a. ms

Ética ambiental. 2004b. ms.

AMES, B. Electoral rules, constituency pressures, and pork barrel: bases of voting in the Brazilian congress. The Journal of Politics, v. 57, p. 324-343, May 1995.

—. The deadlock of democracy in Brazil. University of Michigan Press, 2001.

ARRETCHE, M. Estado federativo e políticas sociais. Rio de Janeiro: Revan, 2000.

CORDEIRO, B. de S. Comitês de bacias: a inscrição do urbano e do social na gestão dos recursos hídricos. In: CARDOSO, Elizabeth Dezouzart; ZVEIBIL, Victor Zaluar (Orgs.). Gestão metropolitana: experiências e novas perspectivas. Rio de Janeiro: Ibam, 1996. p. 131146.

COSTA, Sérgio. Contextos da construção do espaço público no Brasil. Novos Estudos Cebrap, São Paulo: Cebrap, n. 47, p. 179-192, 1997.

- As cores de Ercília: esfera pública, democracia, configurações pós-nacionais. Belo Horizonte: UFMG, 2002.

DROR, Yehezkel. A capacidade para governar: informe ao Clube de Roma. São Paulo: Edições Fundap, 1999.

DUCHACEK, I. D. Comparative federalism. The territorial dimension of politics. Santa Barbara: Holt, Rinehart and Winston Inc., 1970.

FAORO, R. Os donos do poder. Porto Alegre: Globo; São Paulo: USP, 1975. 
FERNANDES, E. "Direito e governança". Cadernos de Textos. Belo Horizonte: Fundação João Pinheiro e Escola de Governo, n. 2, p. ix-xxii. ago. 2000.

FUNDAP (FUNDAÇÃO DO DESENVOLVIMENTO ADMINISTRATIVO). Estruturação de metodologia da governança integrada conjunta - GIC. Relatório, dez. 2004. ms.

FURTADO, Celso. O fator político na formação nacional. Estudos Avançados, São Paulo, v. 14, n. 40, p. 7-12, set./dez. 2000. (Texto em PDF).

GARCIA, Ronaldo Coutinho. Iniqüidade social: como estamos vendo e enfrentando este problema? Brasília: Ipea, 2000. ms.

- Subsídios para organizar avaliações da ação governamental. Brasília: Ipea, jan. 2001. (Texto para Discussão, n. 776).

HAGOPIAN, F. Traditional politics and regime change in Brazil. Cambridge: Cambridge University Press, 1996.

INOJOSA, Rose M. Sinergia em política e serviços públicos: desenvolvimento social com intersetorialidade. Cadernos Fundap, n. 22, 2002.

KING, Preston. Federalism and federation. Baltimore: Johns Hopkins University Press, 1982.

MAINWARING, S. Multipartism, robust federalism and presidentialism in Brazil. In: -; SHUGGART, M. (Eds.). Presidentialism and democracy in Latin America. New York: Cambridge University Press, 1997.

; SAMUELS, D. Federalism, constraints on the central government, and economic reform in democratic Brazil. In: GIBSON, E. Representing regions: federalism and territorial politics in Latin America. (no prelo).

; SHUGGART, M. Presidentialism and democracy in Latin America. Cambridge: Cambridge University Press, 1997.

MANSBRIDGE, J. J. Why we lost the era? Chicago: University of Chicago Press, 1986.

MARTINS, Carlos Estevam. A gestão da água em São Paulo - o feito e o a fazer. In: CONGRESSO ESTADUAL DE COMITÊS DE BACIAS HIDROGRÁFICAS, 1., São Pedro, 2001, Fundap, Anais... São Paulo, 2001. ms.

MATUS, Carlos. Planificación de situaciones. Cidade do México: Fondo de Cultura Económica, 1980.

—. Estratégias políticas: Chimpanzé, Maquiavel e Gandhi. São Paulo: Fundap, 1996. 294 p. 
MELLO, D. L. de. A experiência internacional em gestão metropolitana. In: CARDOSO, Elizabeth Dezouzart; ZVEIBIL, Victor Zaluar (Orgs.). Gestão metropolitana: experiências e novas perspectivas. Rio de Janeiro: Ibam, 1996. p. 19-48.

MELO, M. A. Gestão urbano-metropolitana: neomunicipalismo e empresarialismo local. Cadernos de Textos, Belo Horizonte: Fundação João Pinheiro e Escola de Governo, n. 2, p. 155172, ago. 2000.

MEISSNER, Richard; TURTON, Anthony R. The hydrosocial contract theory and the Lesotho Highlands Water Project. Water Policy, v. 5, n. 2, p. 115-126, 2003.

O’DONNELL, Guillermo. Democracia delegativa? Novos Estudos Cebrap, São Paulo: Cebrap, n. 31, p. 25-40, out. 1991.

- Poliarquias e a (in)efetividade da lei na América Latina. Novos Estudos Cebrap, São Paulo: Cebrap, n. 51, p. 37-61, jul. 1998.

OLIVEIRA, Francisco de. Uma alternativa democrática ao liberalismo. In: IBASE (Org.). A democracia como proposta. Rio de Janeiro: Ibase, 1991.

POLLITT, C. Joined-up government: a survey. Political Studies Review, v. 1, p. 31-46, 2003.

RIKER, W. Federalism, origin, operation, significance. Little, Brown and Company, 1964.

ROLNIK, Raquel; SOMEKH, Nadia. Governar as metrópoles: dilemas da recentralização. São Paulo: São Paulo Perspec., v. 14, n. 4, 2000. Disponível em: <www.scielo.br/scielo.php?script =sci_arttext\&pid=S0102-88392000000400009\&lng=es\&nrm=iso >. Acesso em: 29 set. 2006.

SAMUELS, D. Concurrent elections, discordant results. Presidentialism, federalism, and governance in Brazil. Comparative Politics, v. 33, n. 1, p. 1-20, out. 2000.

SCHWARTZMAN, S. Bases do autoritarismo brasileiro. Brasília: Universidade de Brasília, 1982.

SOUZA, C. Brazil: the prospects of a center-constraining federation in a fragmented polity. Publius, The Journal of Federalism, v. 32, n. 2, p. 23-48, 2002.

SOUZA, M. do C. C. de. Aspectos político-institucionais do federalismo (1930-1964). Relatório de pesquisa do Projeto Balanço e perspectivas do federalismo fiscal no Brasil. São Paulo: Iesp/Fundap, 1994. ms.

TOCQUEVILLE, A. de. A democracia na América. Belo Horizonte: Itatiaia; São Paulo: USP, 1977.

WARNER, J. Integrated management requires an integrated society. Towards a new hydrosocial contract for the 21st century. Pretoria: Awiru, 2000. (Awiru Occasional Paper). 
Water, wine, vinegar, blood. On politics, participation, violence and conflict over the hydrosocial contract (with special reference to the Water War of 2000 in Cochabamba). In: WATER AND POLITICS SEMINAR. Proceedings... Marseille, 2004. Ch. 3.

Mending the GAP: hydropolitical security strategies in the Euphrates Tigris basin. In: WIRKUS, L. (Ed.). Water, development and cooperation - comparative perspective: Euphrates-Tigris and southern Africa. 2005a. (Proceedings of a workshop organized by BIC and ZEF, BICC, Paper n. 46).

- Multi-stakeholder platforms: integrating society in water resource management? Ambiente e Sociedade, v. 8, n. 2, 2005b.

—. More sustainable participation? Multi-stakeholder platforms for integrated resource management. International Journal for Water Resources Development, March 2006.

WEAVER, K. R.; ROCKMAN, B. Do institutions matter? Washington: Brookings Institution, 1993.

WESTER, P.; WARNER, J. River basin management reconsidered. In: TURTON, A. R.; HENWOOD, R. (Eds.). Hydropolitics in the developing world: a southern African perspective. Pretoria: African Water Issues Research Unit (Awiru), 2002. Ch. 5.

WILLIS, E.; GARMAN, C. da C. B.; HAGGARD, S. The politics of decentralization in Latin America. Latin American Research Review, v. 34, n. 1, p. 7-56, 1999.

ZEITOUN, M.; WARNER, J. Hydro-hegemonic theory. A framework for analysis of waterrelated conflicts. Water Policy, 2006.

\section{Web sites}

$<$ www.bndes.gov.br >

$<$ www.eclac.cl $>$

$<$ www.forumoffederations.org >

$<$ www.fundap.sp.gov.br $>$ 